\title{
Thermal and Optical Properties of Regioregular Polythiophene Derivatives Containing Mesogenic Group in the Side Chain
}

\author{
Hiroyuki Kohno, Fumio SAITOH, Takashi MinaRA, and Naoyuki KoIDE ${ }^{\dagger}$ \\ Department of Chemistry, Faculty of Science, Science University of Tokyo, \\ 1-3 Kagurazaka, Shinjuku-ku, Tokyo 162-8601 Japan
}

(Received June 27, 2003; Accepted September 17, 2003)

\begin{abstract}
We synthesized regioregular liquid crystalline polythiophene (PTh) derivatives by chemical oxidative polymerization using iron trichloride to investigate the effect of the regioregularity on their physical properties. The regioregularity was about $90 \%$ for the PTh derivatives. A smectic phase was observed for two PTh derivatives. Plural peaks based on vibronic coupling characteristic of the regioregular PTh derivatives were observed in the $\pi-\pi^{*}$ transition absorption band of the UV-vis spectra. The vibronic coupling disappeared with increasing temperature and a new peak assigned to the PTh derivatives with non-planar conformation for the polymer backbone was observed in shorter wavelength range. The electrical conductivity was about $10^{-3}-10^{-4} \mathrm{~S} \mathrm{~cm}^{-1}$ for the PTh derivatives doped with $\mathrm{I}_{2}$ vapor in the film state.

KEY WORDS Liquid Crystalline Polymer / Regioregular Polythiophene / $\pi$-Conjugated Polymer /

Chemical Oxidative Polymerization /
\end{abstract}

$\pi$-Conjugated polymers were investigated intensively due to their potential applications in electrical and optical devices. The $\pi$-conjugated polymers generally have rigid-rod nature based on the $\pi$-conjugation in the polymer backbone. The rigid-rod $\pi$-conjugated polymers had trouble to process because of their inherent insolubility in common organic solvents and infusibility. The introduction of a flexible long chain into the side chain of the rigid-rod polymer backbone caused a general method for obtaining soluble and fusible rigid-rod polymers. ${ }^{1-6}$

It is well-known that the physical properties of the $\pi$-conjugated polymers are enhanced by the orientation of the rigid-rod polymer backbone. The stretching of the $\pi$-conjugated polymer film, the polymerization in the liquid crystalline matrices under a magnetic field and so on were used to control the orientation of the polymer backbone in the $\pi$-conjugated polymers. ${ }^{7,8}$ Furthermore, controlling the orientation of the polymer backbone in the $\pi$-conjugated polymers was achieved by attaching mesomorphic properties to the $\pi$-conjugated polymers themselves. ${ }^{9-13}$ The electrical conductivity of side chain liquid crystalline polythiophenes(PThs) increased after annealing in the mesomorphic temperature range of them. ${ }^{9-11}$

The regioregularity of the poly(3-alkylthiophenes) (PATs) played an important role for the enhancement of the electrical conductivity. Chen et al. reported that the regioregular PATs exhibited a larger conductivity than the regiorandom PATs. ${ }^{14}$ The regioregular PATs doped with $\mathrm{I}_{2}$ vapor heavily had conductivity around
$10^{3} \mathrm{~S} \mathrm{~cm}^{-1}$, while the regiorandom PATs had conductivity less than $10^{1} \mathrm{~S} \mathrm{~cm}^{-1}$.

Generally regioregular PATs were synthesized using Rieke zinc or Nickel catalyzed cross-coupling. ${ }^{14-17}$ However, the Rieke zinc or Nickel catalyzed crosscoupling would need a special technique to handle for preparing the regioregular PTh derivatives. On the other hand, polymerization of 3,4-disubstituted thiophenes is a useful way to prevent undesirable $\alpha, \beta$ coupling of the thiophene ring. Therefore the polymerization of 3,4-disubstituted thiophene would have a great potential for giving structurally regular PTh derivatives. Leclerc et al. reported that regioregular 3,4disubstituted PTh derivatives were obtained by chemical oxidation of the relative monomers by iron trichloride. ${ }^{18,19}$ This method is very easy way to obtain regioregular PTh derivatives compared to the synthetic methods using Rieke zinc or Nickel catalyzed crosscoupling.

In this study, we synthesized PTh derivatives having a methyl group at 4-position and a mesogenic group at 3 -position in the thiophene ring via a flexible spacer by iron trichloride as a chemical oxidative polymerization catalyst, and investigated regioregularity, thermal, electrical, and optical properties of the PTh derivatives.

\section{EXPERIMENTAL}

\section{Materials}

3-Methoxy-4-methylthiophene (1). Methanol solution of sodium methylate $(28 \mathrm{wt} \%, 30 \mathrm{~mL})$ was dis-

${ }^{\dagger}$ To whom correspondence should be addressed (Tel: +81-3-5228-8248, Fax: +81-3-3235-2214, E-mail: nkoide@ch.kagu.sut.ac.jp). 
solved in $N$-methyl-2-pyrrolidone $(10 \mathrm{~mL})$ under nitrogen atmosphere. After stirring, methanol was evaporated under reduced pressure. 3-Bromo-4-methylthiophene $(5.0 \mathrm{~g}, 28.2 \mathrm{mmol})$ and copper(I) bromide $(1.0 \mathrm{~g}, 7.0 \mathrm{mmol})$ were added to the $N$-methyl-2pyrrolidone solution, and then the reaction mixture was stirred for $90 \mathrm{~min}$ at $110^{\circ} \mathrm{C}$. After salt was removed by filtration, the residue was extracted with diethyl ether. The diethyl ether solution was washed with saturated aqueous solution of ammonium chloride. The diethyl ether solution was dried over magnesium sulfate. The diethyl ether was distilled away. The product was colorless volatile liquid. The product was employed without further purification.

${ }^{1} \mathrm{H}$ NMR $\left(\mathrm{CDCl}_{3}\right) \delta$ ppm: $2.0\left(\mathrm{~s}, 3 \mathrm{H}, \mathrm{CH}_{3}\right), 3.8(\mathrm{~s}, 3 \mathrm{H}$, $\left.\mathrm{OCH}_{3}\right), 6.1(\mathrm{~d}, 1 \mathrm{H}$, thiophene ring $), 6.7(\mathrm{~d}, 1 \mathrm{H}$, thiophene ring).

3-(11-bromoundecyloxy)-4-methylthiophene (2).

Diethyl ether was distilled away from the diethyl ether solution of 3-Methoxy-4-methylthiophene. Toluene $(50 \mathrm{~mL}), \quad 11$-Bromoundecanol $(17.0 \mathrm{~g}, \quad 68.0 \mathrm{mmol})$ and sodium hydrogen sulfate $(6.0 \mathrm{~g}, 43.5 \mathrm{mmol})$ were added to the residue. The reaction mixture was stirred at $100^{\circ} \mathrm{C}$ for $24 \mathrm{~h}$. After toluene was evaporated under reduced pressure, the residue was extracted with diethyl ether. The diethyl ether solution was washed with water until a neutral aqueous solution was obtained. The diethyl ether solution was dried over magnesium sulfate. After diethyl ether was distilled away, the residue was purified by column chromatography (eluent chloroform/hexane $=1 / 5$ ). The product was light yellow oil and was obtained in a $45 \%$ yield $(4.5 \mathrm{~g})$.

IR (neat) $v \mathrm{~cm}^{-1}: 2800-3000\left(\mathrm{CH}_{2}\right.$, methylene group), 1203,1130 (C-O, ether), 852 ( $\mathrm{CH}$, heterocyclic).

${ }^{1} \mathrm{H}$ NMR $\left(\mathrm{CDCl}_{3}\right) \delta \mathrm{ppm}: 1.3-1.9\left(\mathrm{~m}, 18 \mathrm{H}, \mathrm{CH}_{2}\right)$, 2.1 (s, $\left.3 \mathrm{H}, \mathrm{CH}_{3}\right), 3.4\left(\mathrm{t}, 2 \mathrm{H}, \mathrm{CH}_{2}-\mathrm{Br}\right), 3.9\left(\mathrm{~s}, 2 \mathrm{H}, \mathrm{CH}_{2}-\right.$ $\mathrm{O}), 6.1(\mathrm{~d}, 1 \mathrm{H}$, heterocyclic proton $), 6.8(\mathrm{~d}, 1 \mathrm{H}$, heterocyclic proton).

3-\{11-[4-(4'-cyanobiphenyl)oxy]undecyloxy\}-4-methylthiophene (MThO11CN). The compound $2(3.0 \mathrm{~g}$, $8.6 \mathrm{mmol})$ and 4-cyanobiphenol $(4.5 \mathrm{~g}, 23.1 \mathrm{mmol})$ were dissolved in methylethylketone $(80 \mathrm{~mL})$. Potassium carbonate $(10 \mathrm{~g}, 72 \mathrm{mmol})$ and a small amount of potassium iodide were added to the methylethylketone solution. The reaction mixture was refluxed at $100^{\circ} \mathrm{C}$ for $36 \mathrm{~h}$. After the precipitate was removed by filtration, methylethylketone was evaporated to dryness under reduced pressure. The residue was washed with methanol. The product was obtained in a $71 \%$ yield (4.3 g). m.p. $88^{\circ} \mathrm{C}$.

IR ( $\mathrm{KBr}) v \mathrm{~cm}^{-1}: 2800-3000\left(\mathrm{CH}_{2}\right.$, methylene group), $2221(\mathrm{CN}), 1598,1494$ (aromatic group), 1251, 1176
(C-O, ether), $823(\mathrm{CH}$, heterocyclic).

${ }^{1} \mathrm{H}$ NMR $\left(\mathrm{CDCl}_{3}\right) \delta \mathrm{ppm}: 1.3-1.9\left(\mathrm{~m}, 18 \mathrm{H}, \mathrm{CH}_{2}\right)$, 2.1(s, $\left.3 \mathrm{H}, \mathrm{CH}_{3}\right), 3.9\left(\mathrm{t}, 2 \mathrm{H}, \mathrm{CH}_{2}-\mathrm{O}\right), 4.0\left(\mathrm{t}, 2 \mathrm{H}, \mathrm{CH}_{2}-\right.$ $\mathrm{O}), 6.1(\mathrm{~d}, 1 \mathrm{H}$, heterocyclic proton $), 6.8(\mathrm{~m}, 1 \mathrm{H}$, heterocyclic proton), 7.0(d, $2 \mathrm{H}, \mathrm{Ar}-\mathrm{H}), 7.5(\mathrm{~d}, 2 \mathrm{H}, \mathrm{Ar}-\mathrm{H})$, 7.6-7.7(d, $4 \mathrm{H}, \mathrm{Ar}-\mathrm{H})$.

\section{3-\{11-[4-(4'-butoxybiphenyl)oxy]undecyloxy\}-4-} methylthiophene (MThO11Bu). This compound was obtained according to the synthetic method of MThO11CN. The product was obtained in a $78.6 \%$ yield $(1.18 \mathrm{~g})$. m.p. $86^{\circ} \mathrm{C}$.

IR (KBr) $v \mathrm{~cm}^{-1}: 2800-3000\left(\mathrm{CH}_{2}\right.$, methylene group), 1608,1500 (aromatic group), 1243, 1174 (C-O, ether), $825(\mathrm{CH}$, heterocyclic).

${ }^{1} \mathrm{H}$ NMR $\left(\mathrm{CDCl}_{3}\right) \delta \mathrm{ppm}: 1.0\left(\mathrm{t}, 3 \mathrm{H}, \mathrm{CH}_{3}\right), 1.2-1.6(\mathrm{~m}$, $\left.18 \mathrm{H}, \mathrm{CH}_{2}\right), 1.8\left(\mathrm{~m}, 6 \mathrm{H}, \mathrm{CH}_{2}\right), 2.1\left(\mathrm{~s}, 3 \mathrm{H}, \mathrm{CH}_{3}\right), 3.8-$ 4.1(t, $\left.6 \mathrm{H}, \mathrm{CH}_{2}-\mathrm{O}\right), 6.1(\mathrm{~d}, 1 \mathrm{H}$, heterocyclic proton), 6.8 $(\mathrm{m}, 1 \mathrm{H}$, heterocyclic proton $), 6.9-7.0(\mathrm{~d}, 4 \mathrm{H}, \mathrm{Ar}-$ $\mathrm{H}), 7.4-7.5(\mathrm{~d}, 4 \mathrm{H}, \mathrm{Ar}-\mathrm{H})$.

3-\{11-[4-(4' -cyanoazobenzene)oxy] undecyloxy\}-4methylthiophene (MThOllazoCN). This compound was also synthesized according to the synthetic method of the MThO11CN. The product was obtained in a $65 \%$ yield $(3.1 \mathrm{~g})$. m.p. $106{ }^{\circ} \mathrm{C}$.

IR (KBr) $v \mathrm{~cm}^{-1}: 2800-3000\left(\mathrm{CH}_{2}\right.$, methylene group), $2222(\mathrm{CN}), 1597,1498$ (aromatic group), 1579 (azo group).

${ }^{1} \mathrm{H} \mathrm{NMR}\left(\mathrm{CDCl}_{3}\right) \delta \mathrm{ppm}: 1.0\left(\mathrm{t}, 3 \mathrm{H}, \mathrm{CH}_{3}\right), 1.2-1.6(\mathrm{~m}$, $\left.18 \mathrm{H}, \mathrm{CH}_{2}\right), 1.8\left(\mathrm{~m}, 6 \mathrm{H}, \mathrm{CH}_{2}\right), 2.1\left(\mathrm{~s}, 3 \mathrm{H}, \mathrm{CH}_{3}\right), 3.8-$ $4.1\left(\mathrm{t}, 6 \mathrm{H}, \mathrm{CH}_{2}-\mathrm{O}\right), 6.1(\mathrm{~d}, 1 \mathrm{H}$, heterocyclic proton), $6.8(\mathrm{~m}, 1 \mathrm{H}$, heterocyclic proton $), 6.9-7.0(\mathrm{~d}, 4 \mathrm{H}, \mathrm{Ar}-$ $\mathrm{H}), 7.4-7.5(\mathrm{~d}, 4 \mathrm{H}, \mathrm{Ar}-\mathrm{H})$.

\section{PMThO11CN}

The mixture of $\mathrm{FeCl}_{3}(0.5 \mathrm{~g}, 3.1 \mathrm{mmol})$ and distilled chloroform $(40 \mathrm{~mL})$ was stirred for 30 min under nitrogen atmosphere. Chloroform solution $(20 \mathrm{~mL})$ of the monomer (MThO11CN, $1.0 \mathrm{~g}, 2.2 \mathrm{mmol}$ ) was added dropwise to the mixture over $30 \mathrm{~min}$. The reaction mixture was stirred for $24 \mathrm{~h}$ at room temperature under nitrogen atmosphere. After chloroform was evaporated, the residue was poured into large amount of methanol. The precipitate was purified by Soxhlet extraction using methanol and then using acetone. The polymer was dissolved in chloroform, and then the soluble polymer was purified by reprecipitation with acetone. The polymer was purple powder and obtained in a $3 \%$ yield $(30 \mathrm{mg})$. IR (KBr) $v \mathrm{~cm}^{-1}:$ 2962, 2927, $2854\left(\mathrm{CH}_{2}\right.$, methylene group), $2225(\mathrm{CN}), 1602,1495$ (aromatic group).

${ }^{1} \mathrm{H}$ NMR $\left(\mathrm{CDCl}_{3}\right) \delta$ ppm: $1.0-1.8\left(\mathrm{~m}, 18 \mathrm{H}, \mathrm{CH}_{2}\right)$, $2.3\left(\mathrm{~s}, 3 \mathrm{H}, \mathrm{CH}_{3}\right), 3.7\left(\mathrm{~d}, 2 \mathrm{H}, \mathrm{CH}_{2}-\mathrm{O}\right), 4.0\left(\mathrm{~d}, 2 \mathrm{H}, \mathrm{CH}_{2}-\right.$ O), 6.8(d, $2 \mathrm{H}, \mathrm{Ar}-\mathrm{H}), 7.4(\mathrm{~d}, 2 \mathrm{H}, \mathrm{Ar}-\mathrm{H}), 7.6(\mathrm{~d}, 4 \mathrm{H}$, $\mathrm{Ar}-\mathrm{H})$. 
${ }^{13} \mathrm{C} \mathrm{NMR}\left(\mathrm{CDCl}_{3}\right) \delta$ ppm: 13.1, 26.0-31.0, 68.1, 73.5, $110.0,115.0,119.1,127.0,128.3,129.1,131.2,132.5$, $145.2,152.4,159.7$.

\section{PMThO11Bu}

This polymer was synthesized according to the polymerization methods of PMThO11CN. This polymer was purple solid and obtained in a $28 \%$ yield $(0.28 \mathrm{~g})$.

${ }^{1} \mathrm{H} \mathrm{NMR}\left(\mathrm{CDCl}_{3}\right) \delta \mathrm{ppm}: 0.8-1.8\left(\mathrm{~m}, 25 \mathrm{H}, \mathrm{CH}_{2}, \mathrm{CH}_{3}\right)$, 2.2(s, $\left.3 \mathrm{H}, \mathrm{CH}_{3}\right), 3.7-4.0\left(\mathrm{t}, 6 \mathrm{H}, \mathrm{CH}_{2}-\mathrm{O}\right), 6.7-6.9(\mathrm{~d}$, $4 \mathrm{H}, \mathrm{Ar}-\mathrm{H}), 7.3-7.5(\mathrm{~d}, 4 \mathrm{H}, \mathrm{Ar}-\mathrm{H})$.

${ }^{13} \mathrm{C} \mathrm{NMR}\left(\mathrm{CDCl}_{3}\right) \delta$ ppm: 13.1, 13.8, 26.0, 31.0, 68.0, $114.7,119.0,127.6,133.2,152.2,158.1$.

\section{PMThOllazoCN}

$\mathrm{FeCl}_{3} \quad(2.0 \mathrm{~g}, 12.3 \mathrm{mmol})$ was added to the chloroform solution $(50 \mathrm{~mL})$ of the monomer (MThO11azoCN, $1.0 \mathrm{~g}, 2.2 \mathrm{mmol}$ ). The reaction mixture was stirred for $4 \mathrm{~h}$ at room temperature. Chloroform was evaporated and then the residue was washed with large amount of methanol. The black solid obtained was purified by Soxhlet extraction using methanol and then using acetone. The polymer was extracted with chloroform and then the soluble polymer was purified by reprecipitation with methanol. The polymer was obtained in a $15 \%$ yield $(0.15 \mathrm{~g})$.

IR (KBr) $v \mathrm{~cm}^{-1}: 2923,2852\left(\mathrm{CH}_{2}\right.$, methylene group), 2225 (CN), 1598, 1500 (aromatic group), 1581 (azo group).

${ }^{1} \mathrm{H}$ NMR $\left(\mathrm{CDCl}_{3}\right) \delta \mathrm{ppm}: 1.0-1.8\left(\mathrm{~m}, 18 \mathrm{H}, \mathrm{CH}_{2}\right)$, 2.2(s, $\left.3 \mathrm{H}, \mathrm{CH}_{3}\right), 3.8-4.0\left(\mathrm{t}, 4 \mathrm{H}, \mathrm{CH}_{2}-\mathrm{O}\right), 6.9(\mathrm{~d}, 2 \mathrm{H}$, $\mathrm{Ar}-\mathrm{H}), 7.7(\mathrm{~d}, 2 \mathrm{H}, \mathrm{Ar}-\mathrm{H}), 7.9(\mathrm{~d}, 2 \mathrm{H}, \mathrm{Ar}-\mathrm{H})$.

${ }^{13} \mathrm{C} \mathrm{NMR}\left(\mathrm{CDCl}_{3}\right) \delta \mathrm{ppm}: 13.1,26.0-31.0,68.4,73.6$, $113.1,114.8,118.7,119.1,123.1,125.5,126.9,129.1$, $133.1,146.6,152.4,154.7,162.7$.

\section{Characterization}

${ }^{1} \mathrm{H}$ NMR was carried out with a JEOL JNM-LA 400 spectrometer using $\mathrm{CDCl}_{3}$ as the solvent. Infrared spectra were recorded on a JEOL JIR $7000 \mathrm{spec}-$ trometer. Spectra were collected at $4 \mathrm{~cm}^{-1}$ resolution. DSC measurements were conducted with a Mettler DSC821 ${ }^{\mathrm{e}}$. Optical microscopy was performed on a Nikon polarizing optical microscopy, OPTIPHOTOPOL, equipped with a Mettler FP80 controller and a FP82 hot stage. Gel permeation chromatography (GPC) was carried out with a Tosoh HLC-8020 instrument using chloroform as the eluent, equipped with four columns (TSK gel G4000 $\mathrm{H}_{\mathrm{HR}}$, G3000 $\mathrm{H}_{\mathrm{HR}}$, $\mathrm{G} 2000 \mathrm{H}_{\mathrm{HR}}$, and $\mathrm{G} 2000 \mathrm{H}_{\mathrm{HR}}$ ). The instrument was calibrated with a polystyrene standard. UV-vis spectroscopy measurements were carried out with a HITACHI U-3410 spectrophotometer. X-Ray diffraction patterns were recorded with a RIGAKU RINT2500 series with Ni-filtered $\mathrm{Cu}-K \alpha$ radiation. The sample in quartz capillary(diameter $1 \mathrm{~mm}$ ) was held in a temperature-controlled cell (RIGAKU LC high temperature controller). The electric conductivities were measured with a Mitsubishiyuka Loresta HP (MCPT410) electrometer by using four-probe (Mitsubishikagaku MCP-TP06P) technique at room temperature under $\mathrm{N}_{2}$ atmosphere.

\section{RESULTS AND DISCUSSION}

Figure 1 showed chemical structures of synthesized PTh derivatives. We employed a biphenyl group or an azobenzene group as a mesogenic core. We already reported that polarity of the mesogenic terminal group deeply influenced the exhibition of mesophases for the PTh derivatives having a mesogenic group at 3-position in the thiophene ring. ${ }^{9}$ Therefore we introduced a cyano or a butoxy group as a terminal group into the biphenyl group to investigate mesomorphic properties of the PTh derivatives.

Thermal properties and molecular weights of the PTh derivatives were summarized in Table I. A smectic phase was exhibited for PMThO11CN having a polar terminal group, while no mesophases were observed for PMThO11Bu having a non-polar terminal group. This result indicated that the polarity of the mesogenic terminal group would deeply influence the exhibition of the mesophase for the PTh derivatives even if the molecular weights of two PTh derivatives were quite different. In the case of PMThO11azoCN having an azobenzene moiety as a mesogenic core and a polar mesogenic terminal group, two mesophases were ob-
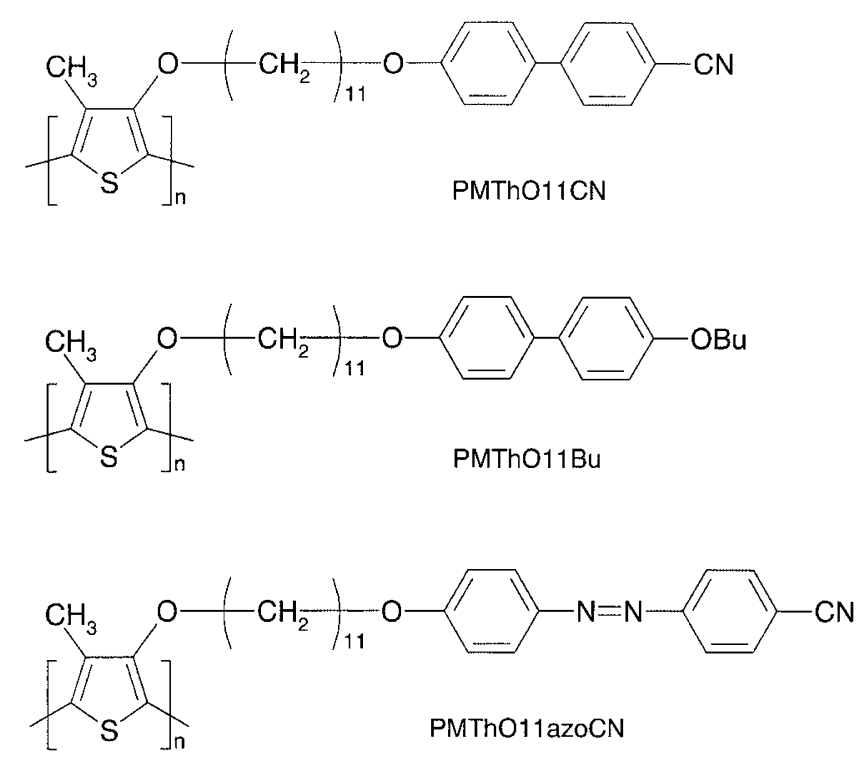

Figure 1. Chemicai structures of polythiophene derivatives. 
Table I. Phase transition temperatures and molecular weights of polythiophene derivatives

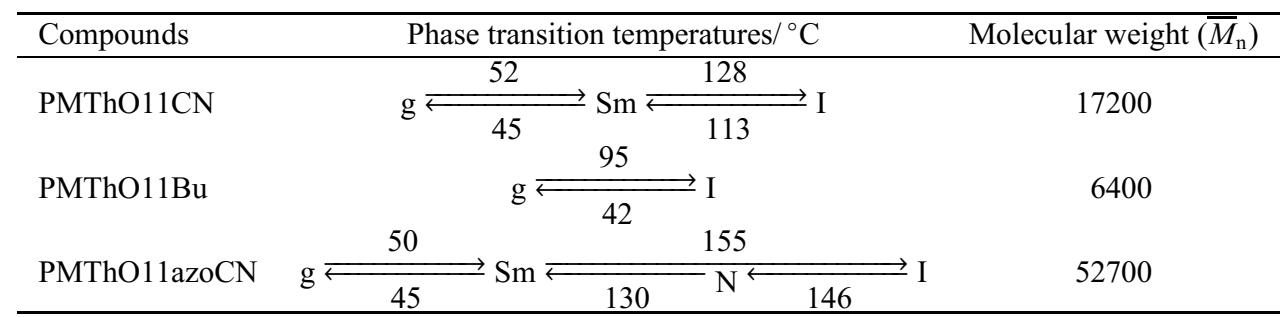

g; glassy, Sm; smectic phase, N; nematic phase, I; isotropic phase.

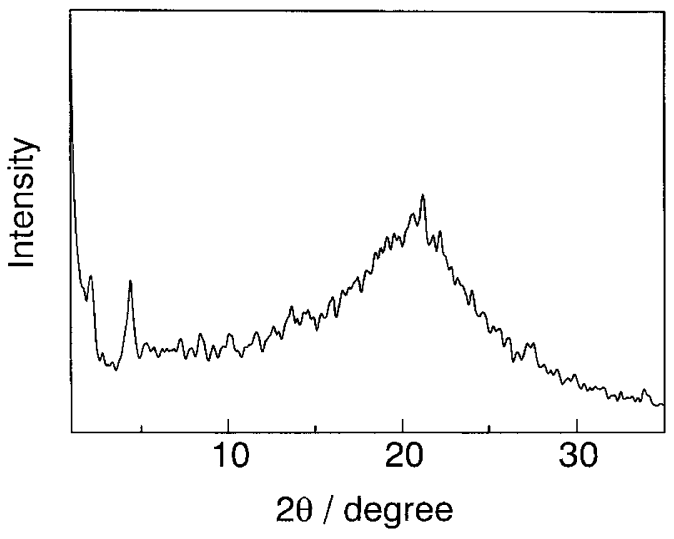

Figure 2. X-Ray pattern polythiophene derivative (PMThO11azoCN).

served on the cooling run. In the mesomorphic temperature range of the PTh derivatives, birefringence was shown, however typical textures characteristic of liquid crystalline phases were not observed.

Figure 2 showed X-Ray patterns of PMThO11azoCN at $120^{\circ} \mathrm{C}$ on the cooling run. Two peaks were observed in the small angle region of the X-Ray pattern for PMThO11azoCN. The d-spacings of the two peaks were $45.3 \AA$ and $21.5 \AA$, respectively. The calculated length of the side chain of PMThO11azoCN was $28.5 \AA$. Therefore, the phase structure of the mesophase would be the bilayer smectic phase. At the present time, the exact structure of mesophase such as smectic $A_{d}$ or smectic $\mathrm{C}$ phase could not be clarified because the optical texture characteristic of a smectic phase could not be observed. A similar X-Ray pattern was also observed for PMThO11CN in the mesomorphic temperature range.

Figure 3 showed ${ }^{1} \mathrm{H}$ and ${ }^{13} \mathrm{C}$ NMR spectra of PMThO11azoCN. The peak near $2.2 \mathrm{ppm}$ in the spectrum was assigned to $\alpha$-methyl protons at the 4-position of thiophene ring. A previous report displayed that the peak assigned to the $\alpha$ - and $\beta$-methylene proton of the alkyl group could be resolved by diad in ${ }^{1} \mathrm{H}$ NMR spectrum of the PATs if they had a regiorandom structure $(50 / 50=$ head-to-tail/tail-to-head $)$ in the polymer backbone. ${ }^{14}$ Therefore the peak was used to determine the regioregularity of the PATs. If the PATs had high regioregular polymer backbone, the peak assigned to the
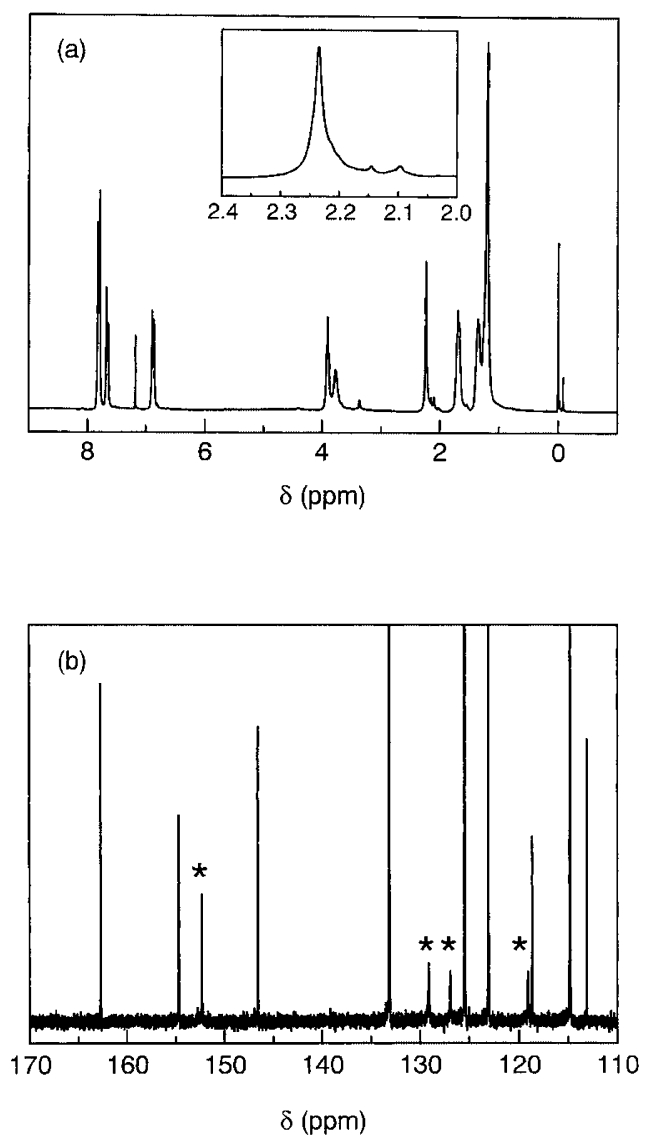

Figure 3. ${ }^{1} \mathrm{H}$ NMR spectrum including expanded spectrum in the range of $2.0-2.4 \mathrm{ppm}$ (a) and ${ }^{13} \mathrm{C}$ NMR spectrum (b) of PMThO11azoCN in $\mathrm{CDCl}_{3} ; \delta$ (ppm) relative to TMS.

$\alpha$ methylene proton should be single. In the ${ }^{1} \mathrm{H}$ NMR spectrum of PMThO11azoCN, the peak near $2.23 \mathrm{ppm}$ was almost single although very small peaks can be observed near $2.1 \mathrm{ppm}$. The regioregularity of PTh derivatives was obtained due to the integration ratios of peaks assigned to the $\alpha$ methylene proton. The regioregularity of PTh derivatives was high and about $90 \%$. Consequently regioregular PTh derivatives were easily prepared by chemical oxidative polymerization of the thiophene derivative having substituted groups at both 3and 4-positions in the thiophene ring.

In the ${ }^{13} \mathrm{C}$ NMR spectra of PTh derivatives, four sharp peaks (asterisked peaks) were observed for the carbon atoms of thiophene ring. Other peaks were assigned to the carbon atoms of mesogenic group in 
Table II. $\pi-\pi^{*}$ absorption maxima and band gap energy of polythiophene derivatives

\begin{tabular}{|c|c|c|c|c|c|}
\hline \multirow{3}{*}{ Compounds } & \multicolumn{5}{|c|}{$\pi-\pi^{*}$ absorption maxima $\left(\lambda_{\max }\right) / \mathrm{nm}$} \\
\hline & \multirow{2}{*}{$\begin{array}{c}\mathrm{CHCl}_{3} \\
\text { solution }\end{array}$} & \multicolumn{4}{|c|}{ Film $^{\mathrm{a}}$} \\
\hline & & & neat & annealed $^{\mathrm{b}}$ & bandgap/eV \\
\hline PMThO11CN & 443 & 511 & 534571 & 538 & 1.95 \\
\hline PMThO11Bu & 441 & 512 & 551603 & $-^{\mathrm{c}}$ & 1.72 \\
\hline PMThO11azoCN & 443 & 508 & 539584 & 540 & 1.92 \\
\hline
\end{tabular}

${ }^{\mathrm{a}}$ At room temperature, ${ }^{\mathrm{b}} \mathrm{PMThO} 11 \mathrm{CN}$ and PMThO11azoCN were annealed at $80^{\circ} \mathrm{C}$ and $100{ }^{\circ} \mathrm{C}$, respectively. ${ }^{\circ}$ Not measured.

the side chain. We confirmed the assignment of the peaks for the PTh derivatives as compared with ${ }^{13} \mathrm{C}$ NMR spectra of the PTh derivatives without mesogenic groups. ${ }^{22}$ Four peaks attributed to the carbon atoms of the thiophene ring were observed in the same range (110-170 ppm) of ${ }^{13} \mathrm{C}$ NMR spectra for the regioregular PTh derivatives without mesogenic groups. The appearance of only four sharp peaks (asterisked peaks) indicated that the PTh derivatives had a homogeneous regioregular structure (head-to-tail head-to-tail linkage) in the polymer backbone. If the PTh derivatives have a regiorandom structure in the polymer backbone, the peaks assigned to the carbon atoms of thiophene ring would be multiple and complicated (16 peaks were assigned to the carbon atoms of thiophene ring for the regiorandom polythiophene). ${ }^{14}$

Figure 4 showed the UV-vis spectra of PMThO11azoCN in the chloroform solution and in the film state. The $\pi-\pi^{*}$ absorption maxima and the band gap of the PTh derivatives were summarized in Table II. A peak near $300-350 \mathrm{~nm}$ was attributed to the absorption of the mesogenic group. The $\pi-\pi^{*}$ absorption maxima was about $440 \mathrm{~nm}$ for the chloroform solution of PTh derivatives. On the other hand, the $\pi-\pi^{*}$ absorption peak of PTh derivatives in the film state were observed near $530-540 \mathrm{~nm}$ and had three absorption maxima based on the vibronic coupling. It is well-known that the vibronic coupling is often observed for the regioregular polythiophenes. ${ }^{18-22}$ Therefore, the appearance of the vibronic coupling in the spectrum would afford us a simple method of a judgment on the regioregular polymer backbone for the PTh derivatives.

We already reported that the annealing process in the liquid crystalline state of the PTh derivatives resulted in the red-shift of the $\pi-\pi^{*}$ absorption peak. ${ }^{11}$ However, in the case of the regioregular PTh derivatives, the annealing process did not lead to the red-shift of the peaks. This result showed that the annealing process would not have enough power to enhance remarkably the planarity of PTh backbones for the regioregular PTh derivatives. The regioregular PTh derivatives in the film state would have a high planar structure in the polymer backbone before annealing.

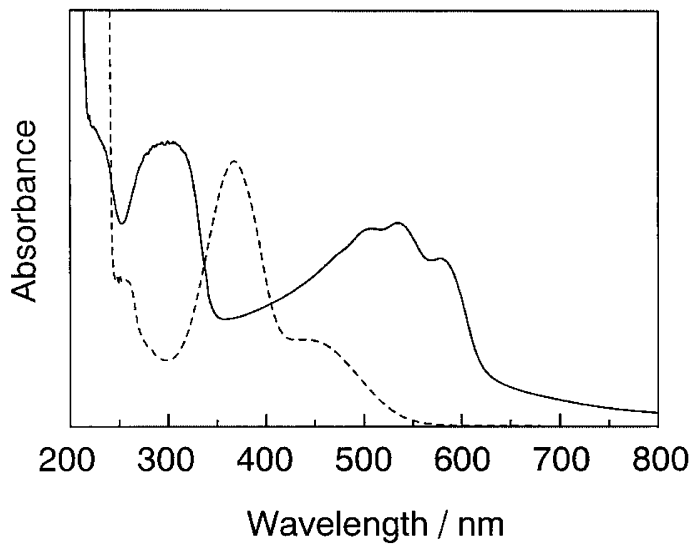

Figure 4. UV-vis spectra of PMThO11CN in chloroform solution (broken line) and in the film state (solid line).

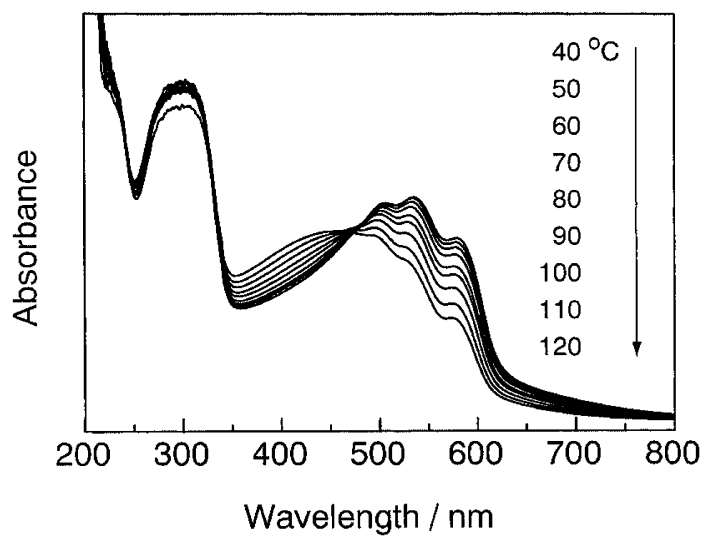

Figure 5. Temperature dependence of UV-vis spectra for PMThO11CN in the film state.

Figure 5 displayed that the temperature dependence of UV-vis spectra for PTh derivatives in the film state. The plural peaks in the longer wavelength would arise from the vibronic coupling. The intensity of the plural peaks became smaller with increasing temperature. The broad peak appeared in the shorter wavelength range (near $440 \mathrm{~nm}$ ). This result showed that the planar conformation of the polymer backbone would transform into the non-planar conformation of it. ${ }^{20,21}$ The vibronic coupling in the longer wavelength range of UV-vis spectrum appeared again with decreasing temperature, although the spectral shape was not exactly identical with that before heating.

The electric conductivity of the PTh derivatives was summarized in Table III. The electric conductivity was 
<smiles>Cc1cscc1Br</smiles>

(2)<smiles>COc1cscc1C</smiles>

(1)

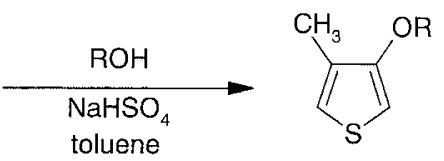

toluene

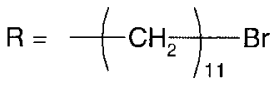

(2)

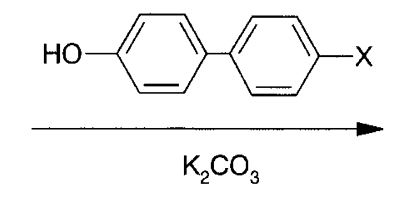

$\mathrm{KI}$

MEK

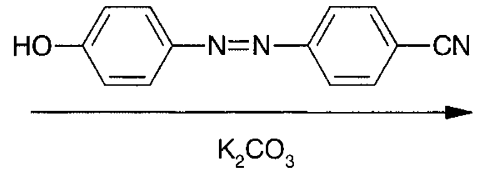

$\mathrm{KI}$

(2)

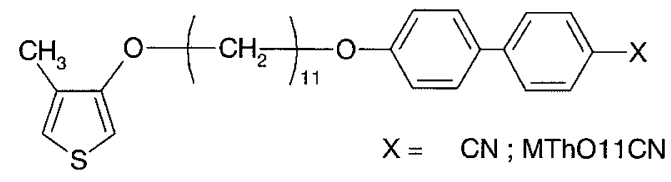

OBu; MThO11Bu

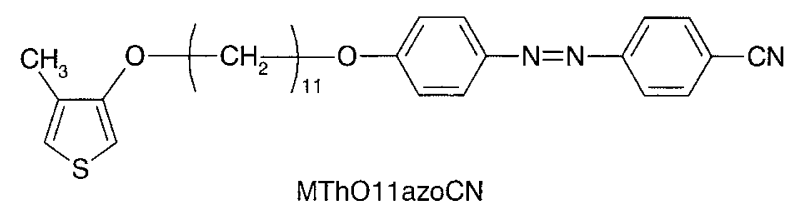

acetone

Scheme 1. Synthesis of thiopene derivatives.

Table III. Electrical conductivity of polythiophene derivatives

\begin{tabular}{lcc}
\hline \multirow{2}{*}{ Compounds } & \multicolumn{2}{c}{ Electrical conductivity $/\left(\mathrm{S} \mathrm{cm}^{-1}\right)^{\mathrm{a}}$} \\
\cline { 2 - 3 } & neat & annealed \\
\hline PMThO11CN & $6.9 \times 10^{-4}$ & $7.6 \times 10^{-4}$ \\
PMThO11Bu & $1.0 \times 10^{-3}$ & $-^{\mathrm{c}}$ \\
PMThO11azoCN & $1.5 \times 10^{-3}$ & $5.1 \times 10^{-3}$ \\
\hline
\end{tabular}

${ }^{\mathrm{a}}$ Iodine doped at r. t., ${ }^{\mathrm{b}} \mathrm{PMThO} 11 \mathrm{CN}$ and PMThO11azoCN were annealed at $80^{\circ} \mathrm{C}$ and $100^{\circ} \mathrm{C}$, respectively.

${ }^{\mathrm{c}}$ Not measured.

about $10^{-3}-10^{-4} \mathrm{~S} \mathrm{~cm}^{-1}$ for the PTh derivatives doped with $\mathrm{I}_{2}$ vapor in the film state. After annealing in the liquid crystalline state, the electric conductivity of the doped PTh derivatives slightly increased.

\section{REFERENCES}

1. K. Yoshino, S. Nakayama, and R. Sugimoto, Jpn. J. Appl. Phys., 26, L1038 (1987).

2. M. Sato, S. Tanaka, and K. Kaeriyama, Makromol. Chem., 188, 1763 (1987).

3. S. Hotta, S. D. D. V. Rughooputh, A. J. Heeger, and F. Wudl, Macromolecules, 20, 212 (1987).

4. M. Leclerc, F. M. Diazu, and G. Wegner, Makromol. Chem., 190, 3105 (1989).

5. M. Sato and H. Mori, Polym. Commun., 32, 42 (1991).

6. G. Zerbi, B. Chierichetti, and O. Inganas, J. Chem. Phys., 94, 4646 (1991).

7. K. Araya, A. Mutoh, T. Narahara, and H. Shirakawa, Chem. Lett., 1984, 1141.
8. K. Akagi, S. Katayama, H. Shirakawa, K. Araya, A. Mukoh, and T. Narahara, Synth. Met., 17, 241 (1987).

9. N. Koide and H. Iida, Mol. Cryst. Liq. Cryst., 261, 427 (1995).

10. N. Koide and N. Moriya, Rep. Prog. Polym. Phys. Jpn., 38, 199 (1995).

11. N. Koide and Y. Hirai, Mol. Cryst. Liq. Cryst., 332, 363 (1999).

12. Y. Watanabe and N. Koide, Mater. Res. Soc. Symp. Proc., 425, 79 (1996).

13. Y. Watanabe, T. Mihara, and N. Koide, Rep. Prog. Polym. Phys. Jpn., 39, 243 (1996).

14. T.-A. Chen, X. Wu, and R. D. Rieke, J. Am. Chem. Soc., 117, 233 (1995).

15. X. Wu, T.-A. Chen, and D. Rieke, Macromolecules, 29, 7671 (1996).

16. R. D. McCullough and R. D. Lowe, J. Chem. Soc., Chem. Commun., 70 (1992).

17. R. D. McCullough, R. D. Lowe, M. Jayaraman, and D. L. Andersom, J. Org. Chem., 58, 904 (1993).

18. M. Leclerc, M. Fréchette, J.-Y. Bergeron, M. Ranger, I. Lévesque, and K. Faïd, Macromol. Chem. Phys., 197, 2077 (1996).

19. I. Lévesque and M. Leclerc, Macromolecules, 30, 4347 (1997).

20. C. Roux, J.-Y. Bergeron, and M. Leclerc, Makromol. Chem., 194, 869 (1993).

21. M. Leclerc, C. Roux, and J.-Y. Bergeron, Synth. Met., 55-57, 287 (1993).

22. K. Tanaka, T. Mihara, and N. Koide, Polym. Prepr., Jpn., 52, 713 (2003). 